DOI https://doi.org/10.36059/978-966-397-242-8-3

\author{
Zhukovska V. V., \\ Candidate of Sciences (Philology), Associate Professor, \\ Department of Cross-Cultural Communication \\ and Foreign Language Education \\ Zhytomyr State Ivan Franko University, \\ Zhytomyr
}

\title{
CURRENT SCHOOLS OF CONSTRUCTION GRAMMAR: THEORETICAL AND METHODOLOGICAL ARCHITECTURE
}

Summary. This study presents the overview of theoretical and methodological assumptions of construction grammar in the interpretation of the framework's current schools. The paper surveys formalists (Berkley Construction Grammar, Sign-Based Construction Grammar), usage-oriented (Cognitive Construction Grammar, Radical Construction Grammar, UsageBased Construction Grammar) and computational language modelling (Fluid Construction Grammar, Embodied Construction Grammar) construction grammar schools. The review presents the most prominent issues of convergence and divergence within each model, focusing, inter alia, on a universal status of linguistic constructions, their quantity and types, issues of constructional compositionality and semantics, reliance on language use data, and specificity of notation systems.

The presented study has demonstrated that construction grammar is a thriving field of grammatical theorizing. Over the past two decades, the framework has become part of the mainstream linguistics, a sophisticated linguistic theory based on a solid cognitive and functional basis, with welldeveloped theoretical and methodological principles. By filling in the gaps in both traditional and formalist descriptions of language, construction grammar blurs the boundaries between vocabulary and grammar, semantics and pragmatics, meaning and use and represents language as a holistic organism. The holistic approach to language units aptly reflects the reality of mental activity, based on uniform cognitive mechanisms and carried out on a single language substrate.

All of linguistic knowledge is a network of form-meaning pairs constructions and nothing else in addition M. Hilpert (2021, p. 6) 


\section{Introduction}

One of the fundamental linguistic concepts is that of a sign - an arbitrary and conventional combination of form (sound form/ signifiant) and meaning (mental concept/ signifé) - elaborated by F. de Saussure in "Cours de linguistique générale" (1916) [3]. At the end of the $\mathrm{XX}^{\text {th }}$ century, the concept of a linguistic sign was significantly reinterpreted on the grounds that arbitrariness in the combination of form and meaning is observed not only for words but also for units at other language levels. This modified understanding of a linguistic sign is called a construction, with construction grammar $(\mathrm{CxG})$ being a recent theoretical framework specifically focused on linguistic constructions [37, p. 80; 39, p. 1].

Construction grammar incorporates leading ideas of several fields of knowledge - linguistic, cognitive, anthropological, philosophical, and computer-oriented, concentrated around the assumption that linguistic form is inextricably linked with its meaning and discoursecommunicative function, and this connection should provide the basis for a descriptively and explanatorily competent theory of language [10, p. 2]. Combining provisions of traditional grammar with postulates of modern linguistic theories of cognitive, functional, and formalist frameworks, construction grammar provides a comprehensive theory of syntactic representation for cognitive linguistics. Epistemologically, the framework aims to explain semiotic phenomena in language and speech on their mental basis and to develop a psychologically plausible description of language as one of the cognitive and social systems available to a human being. Hence, construction grammar is primarily not a theory of language, but a theory of language knowledge based on general cognitive and communicative principles [34, p. 107].

Construction grammar developed in the 80 s of the previous century. Like any other field of knowledge, it did not appear in a theoretical vacuum: its evolution was determined by such domineering linguistic theories as generative grammar, cognitive linguistics, gestalt grammar, and frame semantics. The framework mainly emerged in opposition to generative linguistics. The adherents of the constructional approach rejected the generativist reductionist distinction between vocabulary and syntax and between semantics and pragmatics, claiming that the analysis of language grammar should start with an attempt to provide an adequate description of linguistic idiosyncrasy, i.e., epiphenomenal or epigrammatical units of language. With this in mind, early construction grammarians elaborated the notion of a (grammatical) construction as a fundamental unit of language description. A construction is perceived as 
a semiotic unit that associates a syntactic form with a conventional meaning and defined by interrelated linguistic parameters (prosodic, morphological, syntactic, semantic, discursive-pragmatic). All aspects of a construction are not scattered over different levels of language, but integrated into a holistic linguistic sign. The elements of different levels are not just connected in a construction but are interdependent and interrelated (Fig. 1) [19, p. 256]:

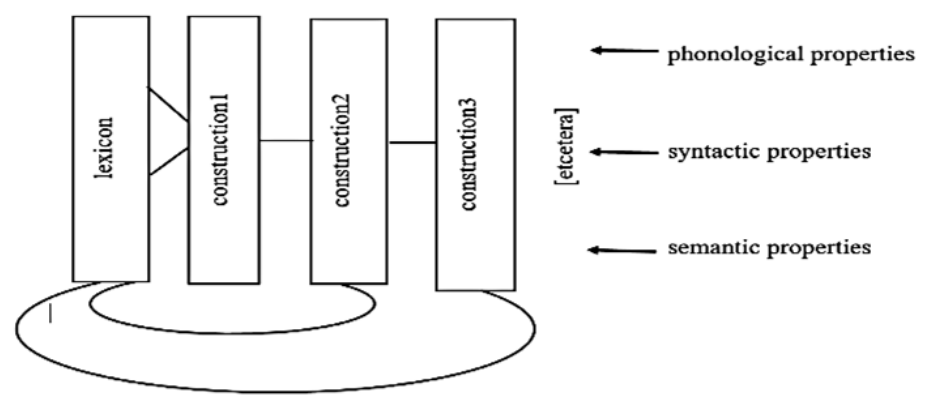

\section{Fig. 1. The model of grammatical knowledge in construction grammar}

Thus, in light of this cognitive-grammatical theory, a conventional linguistic concept of a "construction" receives a new theoretical status of a basic unit of linguistic knowledge. With its roots in traditional grammar, the notion of construction is ascribed a new meaning as a uniform pattern for the representation of all grammatical knowledge - syntax, morphology, and lexicon [17, p. 463]. Constructions are determined as form-meaning pairings, symbolic units that combine linguistic form with conceptual meaning [35, p. 6]. The generalized notion of a construction applies to any grammatical structure. Everything in language, from morphemes and words to idioms, collocations, abstract phrasal patterns, and clauses, can be characterized as constructions. Knowledge of language is reconceptualized as knowledge of a network of constructions.

A linguistic construction is a mental construct (gestalt), fixed in speech and mental activity of language speakers as a result of their interaction with each other and with objects of the surrounding world. It is a minimal operational linguo-cognitive unit for language analysis and representation. As complex semiotic units, non-compositional cognitively motivated pairings of a certain form (constituent elements) 
and meaning/ (discourse or pragmatic) function, constructions are stored in the minds of speakers as holistic, conceptually connected, and interacting structures, serving as a cognitive-semantic interface to knowledge structures behind their plane of expression [30; 31; 47, p. 7].

From CxG point of view, language constitutes a system of interconnected constructions. The complete list of constructions that make up a speaker's mental grammar is stored in the construct-i-con [28], a structured inventory of taxonomic structural networks. Hence, linguistic competence presupposes a speaker's knowledge of the complete inventory of language constructions, and the driving force in language acquisition is social interaction, enhanced by general learning mechanisms, such as the ability to perceive meaningful patterns and correspondences in perceptual data and make productive generalizations from these observations [33, p. 337].

Over the past two decades, construction grammar has become part of the mainstream linguistics, a sophisticated linguistic theory based on a solid cognitive and functional basis, with well-developed theoretical and methodological principles. While most early construction grammarians focused on idiosyncratic "peripheral" constructions (in particular, idiomatic constructions), from the mid-1990s to the early 2000s the constructional approach expanded the research scope including the study of "central" and less idiosyncratic constructions. This expansion of the research material was the next logical step towards evolution of construction grammar as a comprehensive grammatical model of linguistic analysis.

Today, construction grammar represents a cluster of cognitive linguistic theories of grammar. Most reviews of the framework $[17 ; 30 ; 34 ; 36]$ identify several construction-oriented schools, the leading ones being Berkeley Construction Grammar (Ch. Fillmore, P. Kay), Sign-Based Construction Grammar (I. Sag, H. Boas), Cognitive Construction Grammar (A. Goldberg), Radical Construction Grammar (W. Croft), Fluid Construction Grammar (L.Steels), and Embodied Construction Grammar (B. Bergen, N. Chang). Despite conforming to essential tenets of the constructional approach: the independent existence of constructions as symbolic units, the uniform representation of grammatical information, and the taxonomic organization of constructions in language [17, p. 479], construction grammar schools differ from one another on several issues.

Regardless remarkable advances in the field of construction grammar in western linguistics, constructionally oriented studies in this country are still lacking. To date, only few Ukrainian scholars promote 
construction-oriented research. Specifically, Professor S.A. Zhabotynska integrates the basic principles of the constructional approach into her cognitive linguistic theory 'Semantics of lingual networks' [1]. Professor S.I. Potapenko's research focuses on the study of paradigmatic and syntagmatic relations between constructions in English journalistic discourse [49]. Professor G. Sytar conducts construction-oriented studies on the material of the Ukrainian language [2]. In her doctoral research, the linguist implements a constructivist approach to analyze the linguistic properties of Ukrainian syntactic phraseologisms.

Acknowledging the framework's obvious research potentiality, this article surveys the current schools of construction grammar and gives an abstract exposition of their theoretical and methodological architecture with the aim of popularizing this innovative approach to language study among Ukrainian linguistic community. Concentrating specifically on the most prominent issues of convergence and divergence within each model, the paper discusses formalist (Berkley Construction Grammar, Sign-Based Construction Grammar), usage-oriented (Cognitive Construction Grammar, Radical Construction Grammar, Usage-Based Construction Grammar) and computational language modelling (Fluid Construction Grammar, Embodied Construction Grammar) constructional schools.

\section{Formalist schools of construction grammar}

The school of Berkeley Construction Grammar (BCG) was developed by Charles Fillmore and his collaborators at the University of California (Berkeley, USA) in the late 1980s and early 1990s. Theoretical and methodological assumptions of the school are set out in the article "The Mechanisms of "Construction Grammar'" (1988), in which Ch. Fillmore enunciates the fundamental principles of construction grammar and outlines the crucial distinctions between the constructional approach, transformational grammar, and grammar of phrasal structures. The researcher stresses the importance of "non-central constructions of language" [23, p. 36] and proclaims the description of formal properties of grammatical constructions alongside their semantic and pragmatic properties.

A first and rather general definition of a construction as a special linguistic unit, whose aspects of the structure or meaning cannot be derived from the meaning or form of its constituent parts, is offered in the paper "Syntactic Intrusions and the Notion of Grammatical Construction" (1985) [24]. Ch. Fillmore outlines semantic and pragmatic patterns of a sentence structure reorganization based on the analysis of "irregular" cases of syntactic "intrusion", i.e., introduction into the sentence structure additional 
morphological elements (e.g., redundant HAVE: If you had 've eaten it, you would have died), phrases (e.g., THE-phrases (the hell, the devel, the heck etc.): What the heck did you see?) and displacement structures in which the constituent is placed with a certain grammatical or rhetorical purpose in one part of the sentence, and interpreted in another (e.g., What big teeth you have). The linguist consistently substantiates the advantages of one-level representation of such complex syntactic structures in terms of constructions over multi-level transformational analysis.

For example, analyzing cases of intrusion of THE-phrase, the linguist proves its probability in the sentence types that meet specific restrictions. Representation of these restrictions is possible only by postulating a special construction, presented in the diagram-container (Fig.2). As can be seen from Figure 2, the intrusion of the specified element is possible only in interrogative sentences with a WH-phrase (except WHICH) in the initial position, followed by an inserted lexeme with specific meaning (the hell, the devil, the heck, etc.). On the example of the phenomenon of syntactic intrusion $\mathrm{Ch}$. Fillmore explains the structural reorganization of a sentence structure by context-dependent mechanisms, arguing that the introduction and movement of lexical and phrasal elements in a sentence is conditioned by semantic and pragmatic properties of the host construction. Its syntactic organization and basic meaning (function) are the factors determining selection of certain lexical units during the statement generation [24].

In successive studies, Charles Fillmore and his proponents analyze several constructions of the English language, with particular emphasis on idiosyncratic expressions and idioms. Specifically, in the authoritative paper "Regularity and idiomaticity in grammatical constructions" (1988), Ch. Fillmore, P. Kay, and C. O'Connor perform a comprehensive multilevel study of the English construction let alone and present an algorithm for analyzing a grammatical construction on syntactic, semantic, and pragmatic levels [26]. The researchers demonstrate that the components of each level and their semantics are involved in the linguistic representation of the construction and are firmly interconnected and interrelated. It should be noted that, focusing primarily on idiomatic constructions, early constructional grammarians also paid attention to regular and central grammatical constructions, suggesting that the same analytical tools can be exploited to study both basic structures and "special" cases [25, p. 112]. 


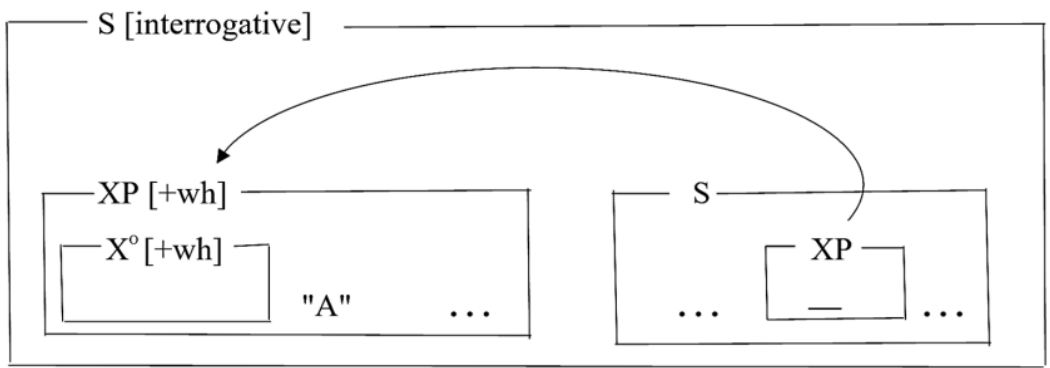

\section{Fig. 2. № Modeling of the inserted THE-phrase construction}

BCG is a formalist theory of language that utilizes a unification-based model to represent grammatical information. Each construction corresponds with more or less detailed information about its phonological, morphological, syntactic, semantic, pragmatic, and prosodic properties. Linguistic properties of a construction are uniformly represented in a formal notation based on nest diagrams, feature structures, and coindexation. The notation represents two levels of linguistic information specification: construction-level information and constituent-level information. Hence, two planes of representation are specified: external (EXTERNAL) characteristics of a construction as a holistic unit (parent structure) and its internal (INTERNAL) organization (daughter structures as constituents of a construction). The representation of external properties of a construction involves specification of constraints determining the ability of a construction to be part of higher-level constructions and interact with them, and representation of internal structure of a constriction includes specification of the requirements for all its constituents. The distinction between the two types of information on the properties of a construction allows to formulate both systemic generalizations about the syntagmatic constraints of a construction and provide comprehensive information about its internal structure.

Fig. 3 presents a formal representation of linguistic parameters of the English Subject-Predicate construction as a maximally generalized pattern for instantiating an unlimited number of constructs with the same general structural and relational parameters.

Figure 3 shows that in the external syntax the Subject-Predicate construction is a phrase pattern with a verb as its head, which cannot be further extended because all requirements for the subject are fulfilled $([\max +$, subj +$])$. The external semantics of the construction integrates 
the semantics of the daughter constituents: the inherent meaning and function of the subject NP and the (composite) value of the VP phrase, which is indexed by the arrow $(\downarrow)$ on the diagram. Representation of the internal properties of the construction demonstrates that it comprises two daughter constituents: a subjective complement and a constituent with a verb head that requires a subject. The relations between the constituents of the construction are represented by co-indexation (\#2) between the left daughter constituent and the corresponding element in the valence specification in the right daughter constituent.

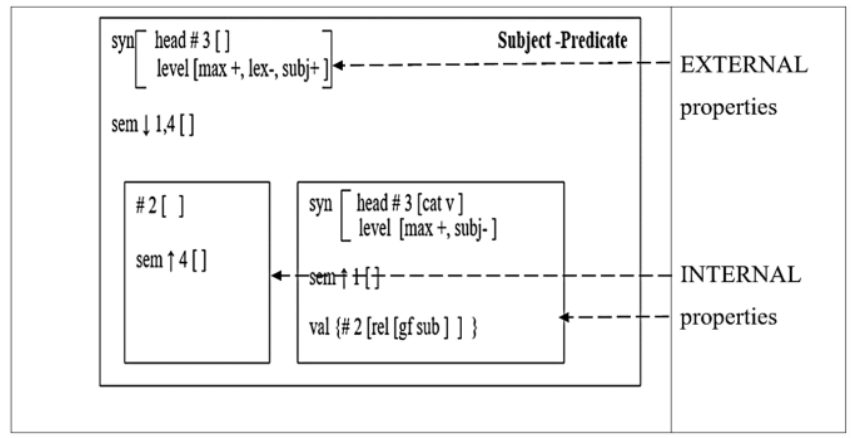

\section{Fig. 3. Linguistic parameters of the Subject-Predicate construction in the formalism of Berkeley Construction Grammar [from 27, p. 61]}

Broadly speaking, Berkeley Construction Grammar is a generative model. Pointing out the distinctive features of construction grammar, P. Kay defines the framework as a non-modular, generative, nonderivational, one-level, unification-based grammatical theory, which aims to fully cover the facts of any language with no loss of linguistic generalizations in a language and between languages [42, p. 171]. Despite a general generative basis, BCG maintains a pronounced cognitive character and shares with R. Langacker's cognitive grammar (CG) several significant insights. First, both approaches agree that idiomatic units should be treated as central rather than peripheral units of the language system. Second, both approaches recognize that the unit of analysis should be a construction that uniformly and holistically represents syntactic, semantic, pragmatic (and phonetic) information, thus adhering to the thesis of the symbolic nature of language units. Third, both BCG and CG use an inventory approach to a psychologically plausible 
representation of the language system, assuming that language mechanisms are not aimed entirely at building the language structure, but rather at preserving it in complex networks of interrelated constructions [22, p. 660-661]. At the same time, R. Langacker's cognitive grammar adopts a usage-based approach to language study, while construction grammar presented by Ch. Fillmore, P. Kay, and their followers is based on the generative principles of language competence. Even though Berkeley Construction Grammar does not represent a fullfledged cognitive field, it is recognized as an influential cognitive approach to grammar [22, p. 661], which laid the foundation for all other schools of construction grammar.

Today, M. Fried, J.-0. Östman, T. Ohori, and others [27; 46; 47] are working on an updated and modified version of Berkeley Construction Grammar, while the school's founders, Ch. Fillmore and P. Kay reoriented their scientific interests. Ch. Fillmore focused on the FrameNet project, where he implemented the ideas of frame semantics, and P. Kay together with A. Sag and L. Michaelis collaborated on the development of another formalized construction-oriented school - Sign-Based Construction Grammar.

Sign-Based Construction Grammar (SBCG) (I. Sag, L. Michaelis) combines research ideas evolved over a quarter of a century in the field of Head-Driven Phrase Structure Grammar with studies in the tradition of Berkeley Construction Grammar [51]. SBCG is intended to expand the empirical principles of Head-Driven Phrase Structure Grammar and provide Berkeley Construction Grammar with a better grounded theoretical foundation. Sign-Based Construction Grammar is a formalized version of BCG [55], with a number of essential innovations in the notation system. The analytical accuracy of this constructional approach contributes to a more straightforward empirical prediction and refutation of linguistic phenomena, increased comparability of data between languages, and general theoretical accuracy of linguistic analysis.

The central purpose of the school lies in the development of a formalized theory to establish universal language properties, in particular recursion, which is generally given scant attention in other models of construction grammar. The school defines language as a system of signs. Subtypes of signs are a word, lexeme, and phrase, which are characterized by such parameters as phonetic structure, (morphological) form, syntactic category, semantics, and contextual factors, including information structure [50, p. 71]. Signs are represented as feature structures, organized in an inheritance-based hierarchy. Signs 
are licensed in two ways: by a lexeme or a construction. Hence, the grammar of language consists of a lexicon, i.e., a limited set of lexical descriptions (descriptions of the structures of the features of the types of lexeme or word) and a set of constructions. An illustration of the feature structure of a lexeme type sign (verb drink) is demonstrated in Fig. 4:

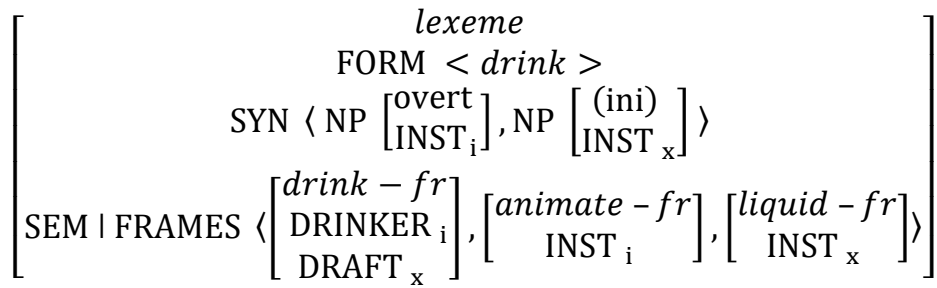

\section{Fig. 4. Representation of the lexeme 'drink' in the formalism of Sign-Based Construction Grammar}

As seen from Figure 4, the semantic properties of the verb lexeme drink are represented by semantic frames (drink-fr, animate-fr, liquid-fr), which specify the features of the elements that are part of it. In particular, the element DRINKER is a living being, and the substance consumed is a liquid. The combinatorial properties of the verb lexeme drink are represented by a value valence (VAL) of the attribute SYN, which specifies the elements of the valence frame of the verb. Accordingly, the valence frame of the drink lexeme includes two valents, represented in the scheme by nominative phrases (NP): the first NP is co-indexed with the participant DRINKER $\mathrm{i}_{\mathrm{i}}$ in the semantic frame drink, and the second is coindexed with the participant DRAFTx. Each of the valents specifies its instantiation properties: the first valence (subject NP) is obligatorily expressed (overt), and the second is optionally instantiated (ini).

Words and lexemes are interpreted as individual signs, while constructions are identified as combinations of signs - constructs (cxt). In SBCG model, the construction represents only the mother sign of the construct (parent in BCG), which has no daughters, but only specifies the list-valued attributes. Modeling of constructional parameters in the interpretation of SBCG is illustrated by the example of the SubjectPredicate construction (Fig. 5) [50]: 


$$
\text { subjpred }-c x t \rightarrow\left[\begin{array}{c}
\text { phrase } \\
\text { MTR }[\text { SYN }[\text { VAL }<>]] \\
\text { DTRS }<\mathrm{X}, \mathrm{H}> \\
\mathrm{HD}-\mathrm{DTR} \mathrm{H}\left[\mathrm{SYN}\left[\begin{array}{l}
\mathrm{CAT}[\mathrm{VF} \text { fin }]] \\
\mathrm{VAL}<\mathrm{X}>
\end{array}\right]\right.
\end{array}\right]
$$

\section{Fig. 5. Representation of the Subject-Predicate construction in the formalism of Sign-Based Construction Grammar}

The given scheme shows that the Subject-Predicate construction is a mother sign of a phrase type, representing a simple sentence in English. The construction includes features of a mother sign (MTR), in which the value of VAL (ENCE) is unspecified, and features of daughter constituents (DTRS), the value of VAL of which are valence signs of two daughter signs $\mathrm{X}$ and $\mathrm{H}$. The head daughter constituent expressed by a finite verb has only one element in the VAL specification (X). The daughter constituent $\mathrm{X}$ represents the subject of the sentence.

If Berkeley Construction Grammar and Sign-Based Construction Grammar represent a "formalist" tradition in the constructional approach, Cognitive Construction Grammar and Radical Construction Grammar share the ideas of a usage-oriented approach to language study.

\section{Usage-oriented schools of construction grammar}

Usage-oriented or usage-based models of construction grammar follow a general cognitive commitment to explore and interpret the facts of language from a functionally dynamic aspect. Accordingly, language is built from events of real use and understood as an inventory of dynamic sign conventions (constructions), constantly updated by language use.

The nomination "usage-based" was first suggested by R. Langacker [45, p. 494] in the late 80 s of the $\mathrm{XX}^{\text {th }}$ century to characterize linguistic approaches that did not support a strict distinction between knowledge of language (competence) and its use (performance). The construction grammar schools adhering to the principles of usage-based theory of language include Cognitive Construction Grammar and Radical Construction Grammar.

Cognitive Construction Grammar (CCG) (A. Goldberg) incorporates the key ideas of R. Langacker's cognitive grammar [45], Ch. Fillmore's construction grammar [25], and G. Lakoff and M. Johnson's theory of conceptual metaphor [44], and focuses on establishing general cognitive 
principles substantiating language-specific constructions. A. Goldberg's landmark monograph "Constructions: A Construction Grammar Approach to Argument Structure" (1995) is the most authoritative research in the field. In this book, the researcher consolidates the concept of a "construction" as a theoretical concept of a novice grammar theory and implements the principles of construction grammar to regular constructions [28]. Linguistic constructions are viewed as structuralsemantic primitives, but not as "taxonomic epiphenomena" [22, p. 667].

A. Goldberg's classical linguistic definition of a construction states that " $\mathrm{C}$ is a CONSTRUCTION iff ${ }_{\text {def }} \mathrm{C}$ is a form-meaning pair $<\mathrm{F}_{\mathrm{i}}, \mathrm{S}_{\mathrm{i}}>$ such that some aspect of $F_{i}$ or some aspect of $S_{i}$ is not strictly predictable from C's component parts or from other already established constructions" [28, p. 4]. The form of a construction is motivated by its meaning, which is interpreted as a cognitive basis, a speaker's idea of the situation. Following the cognitive commitment, the researcher points out that all properties of a language directly reflect human experience, conceptualization, and construal of the surrounding reality. The central or prototypic meaning of a specific construction is salient as it represents the basic situations of human experience. This idea is reflected in the Scene Encoding Hypothesis, which stipulates that central (prototypic) senses of constructions correspond to basic sentence types encoding event types that are basic to human experience [28, p. 39].

A. Goldberg focuses on the argument structure of a group of sentencelevel constructions in English. The researcher analyses five basic structural patterns (propositions) of a simple sentence, which instantiate basic semantic scenarios of events and are associated with a fixed set of arguments and thematic roles, determined by a specific construction (Table 1) [28]:

A. Goldberg's cognitive construction grammar differs from other grammatical theories in postulating an equal status of all constituents in a construction and their dependence on a construction's basic meaning. In contrast to the predicate-argument approach that assigns a central place in a sentence structure to the verb-predicate determining the quantity and quality (semantic and morphological properties) of its actants [5, p. 288-289], A. Goldberg argues the semantic structure of a construction itself determines its arguments. Denoting participants of an event, the arguments of a construction receive the status of a construction's constituents but not of a verb's actants, because their dependence on semantic and valence properties of the verb-predicate is weakened by the semantics of a construction. All constituents of a 
construction are of equal status, and a verb is only one of the components in a construction necessary for meaning formation in a sentence or statement. A construction is endowed with its own semantics, which does not depend on the lexical units used in it $[28$, p. 1]. The equal status of a verb and other arguments deprives a verb of its central role in a construction, while a construction is considered not as a verb-centric, but rather as a verb-oriented structure.

Table 1

\section{Argument structure constructions in English}

\begin{tabular}{|c|c|c|}
\hline 1. Ditransitive & $\mathrm{X}$ CAUSES Y to RECEIVE $\mathrm{Z}$ & $\begin{array}{l}\text { Subj V Obj Obj2 } \\
\text { Pat faxed Bill the letter. }\end{array}$ \\
\hline 2. Caused Motion & $\mathrm{X}$ CAUSES Y to MOVE Z & $\begin{array}{l}\text { Subj V Obj Obl } \\
\text { Pat sneezed the napkin off } \\
\text { the table. }\end{array}$ \\
\hline 3. Resultative & $\mathrm{X}$ CAUSES Y to BECOME $\mathrm{Z}$ & $\begin{array}{l}\text { Subj V Obj Xcomp } \\
\text { She kissed him unconscious. }\end{array}$ \\
\hline 4. Intransitive & X MOVES Y & Subj V Obl \\
\hline Motion & & $\begin{array}{l}\text { The fly buzzed into the } \\
\text { room. }\end{array}$ \\
\hline 5. Conative & X DIRECTS ACTION at Y & $\begin{array}{l}\text { Subj V Oblat } \\
\text { Sam kicked at Bill. }\end{array}$ \\
\hline
\end{tabular}

The processes of interaction between verbs and sentence-level constructions are explained by A. Goldberg in terms of frame semantics. Depending on semantics, a verb correlates with a certain participant role of some type of event, and a construction positions argument roles, which also correlate with a certain type of event. For example, the verb 'buy' is associated with such participant roles as BUYER, SELLER, and GOODS, and the verb 'sing' is associated with the roles SINGER and SONG. Argument roles of sentence-level constructions are of a more generalized character and are known in the specialized literature as semantic (thematic) roles (AGENT, PATENT, THEME, EXPERINCER, etc.) [22, p. 674].

A verb determines what participant roles are lexically profiled or conceptually salient, while sentence-level constructions profile their argumentative roles. In A. Goldberg's vision, lexical profiling refers to an aspect of the meaning of a linguistic expression activated by certain units within a corresponding semantic frame, and constructional profiling concerns the realization of argumentative roles in terms of nuclear 
grammatical relations. Certain arguments of a verb can be lexically profiled, but not profiled by a construction.

The fusion of semantic and structural properties of an individual verb and a grammatical construction is determined by two principles that govern the association of participant roles of a verb with argument roles of a construction - the Semantic Coherence Principle and the Correspondence Principle. According to the Semantic Coherence Principle, "only roles which are semantically compatible can be fused. The two roles $r_{1}$ and $r_{2}$ are semantically compatible if either $r_{1}$ can be construed as an instance of $r_{2}$, or $r_{2}$ can be construed as an instance of $r_{1} \ldots$ Whether a role can be construed as an instance of another role is determined by general categorization principles" [28, p. 50]. The Correspondence Principle states that "each participant role that is lexically profiled and expressed must be fused with the profiled argument role of the construction. If a verb has three profiled participant roles, then one of them may be fused with a nonprofiled argument role of a construction" [28, p. 50].

Schematic representations in A. Goldberg's model include at least two levels: SEM(antics), representing the semantic structure of a construction in terms of argument roles, and SYN(tax), specifying the syntactic organization of a construction in terms of how grammatical functions of the subject and object implement the argument roles. The 'PRED' slot represents the potential for a particular verb to be mapped onto a construction, and the blank angle brackets indicate the potential possibility that participant roles of that verb will fuse with the argument roles of a construction. For example, Fig. 6 and Fig. 7 demonstrate representations of the Ditransitive construction and the Ditransitive construction with the verb 'send' [28, p. 55].

Linguistic constructions form structured networks in which the interaction between constructions is determined by the relations of inheritance, including polysemy links, subpart links, instance links, and metaphorical extension links.

\begin{tabular}{|c|c|c|c|c|}
\hline Sem & CAUSE-RECEIVE & $<$ AGENT & RECIPIENT & PATIENT> \\
\hline & SEND & $<$ SENDER & SENDEE & SENT > \\
\hline Syn & $\mathrm{V}$ & SUBJECT & OBJ & $\mathrm{OBJ}_{2}$ \\
\hline
\end{tabular}

\section{Fig. 6. Representation of the Ditransitive construction from the perspective of Cognitive Construction Grammar}




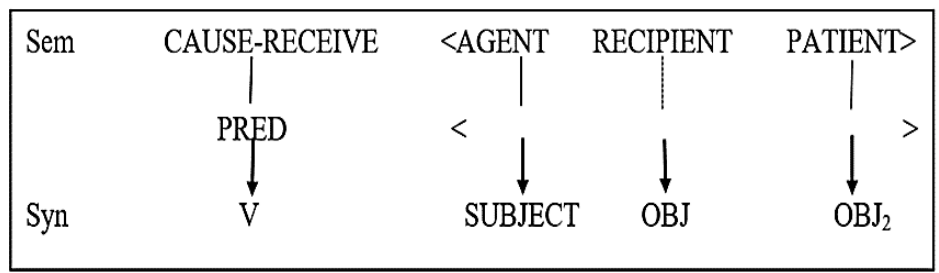

\section{Fig. 7. Representation of the Ditransitive construction with the verb 'send' from the perspective of Cognitive Construction Grammar}

Radical Construction Grammar (RCG) is designed by W. Croft $[15 ; 18]$ to consider typological variation from a construction grammar perspective and to account for certain issues of syntactic argumentation. In many respects, $\mathrm{W}$. Croft adopts the assumptions of cognitive grammar, cognitive construction grammar, and the usage-based theory of language. Like CG, Radical Construction Grammar does not assume the distinction between syntactic and semantic levels in grammatical constructions and postulates the existence of a lexical-grammatical continuum, represented by cognitive-semantic schemas correlating with specific facts of language. W. Croft argues that the lexical-grammatical continuum and mental grammar are enshrined in the minds of speakers in the form of a structured inventory of constructions. A construction is understood as the essential unit of language of a simple or complex structure with a prototypical or more differentiated meaning.

W. Croft considers constructions to be basic units of syntactic representation, and grammatical categories are derived from the constructions in which they are used [15, p. 4]. A construction is recognized "an entrenched routine ('unit'), that is generally used in the speech community ('conventional'), and involves a pairing of form and meaning" [16, p. 274]. The linguist emphasizes the similarity of constructions and words, which is manifested in their symbolic nature, as these units combine syntactic and phonetic (form) with semantic, contextual or discursive (meaning /function) information. Constructions embrace all language units - from morphemes to sentences. RCG denies the compositionality of a construction, i.e., constructions are not constituted by elements of lower levels of the hierarchy (for example, words), but words can be distinguished as a result of successive 
processing procedures from the whole construction [18]. Knowledge of constructions arises from the real use (usage-based approach) of language and reflects the processes of entrenchment of language structures in a language community [22, p. 693].

The crucial difference (radicalism) of W. Croft's model of construction grammar lies in the fact that in this interpretation all grammatical categories are oriented toward a specific language and its constructions. The researcher argues that there are no universal principles, syntactic categories, roles and relations; they are unique both to different language systems and to different constructions. Accordingly, there are no universal formal categories, as such categories are unique to a particular language and a particular construction. Put differently, constructions are language-specific, and language categories are defined specifically for a particular language in terms of the constructions they occur in. For example, 'intransitive verb' is recognized as a category of English but not of universal grammar. Parts of speech are understood in relation to constructions "expressing propositional acts (referring constructions, predication constructions, modifying/ attributive constructions, etc.)" [2013, p. 218]. Ultimately, universal are parameters that regulate relations between form and meaning in grammatical constructions [22, p. 692-697]. W. Croft's school of construction grammar emphasizes the taxonomic nature of knowledge of constructions, grounded on relations of hierarchical inheritance.

Usage-based Construction Grammar (UBCG) integrates theoretical and methodological premises of construction grammar in its traditional (Ch. Fillmore, P. Kay) and cognitive (A. Goldberg, W. Croft) interpretations with the key concepts of the usage-based theory of language (R. Langacker, M. Barlow, S. Kemmer, M. Tomasello), quantitative-corpus linguistic studies (J.Bybee) and quantitativesemantic syntax (A. Stefanowitsch, St. Gries, T. Hoffmann).

Most linguistic research of the previous century operated on the structuralist and generativist postulate that the study of the language system should be performed independently from its functioning. The legitimacy of this view has been questioned by usage-oriented researchers and psycholinguists, whose research has proven a close relationship between the structure of language and its use, providing convincing evidence that the structure and organization of language knowledge by a speaker are shaped by language use. 
Originating as a reaction to the domineering generative paradigm at the end of the XX ${ }^{\text {th }}$ century in the studies of R. Langacker $(1987,1988)$, the usage-based theory of language study is a comparatively recent linguistic approach, which has already become an influential trend in linguistics of recent decades. This approach has caused a radical change in the "theoretical landscape of linguistics" [32, p. 1] and shifted a research focus from 'system' to 'usage' and from 'language' to 'speech'.

Usage-based linguistic models do not support the generativist distinction between language competence and language use (performance). The key usage-based principle claims that the language system is the product of its functioning [41, p. 10], the study of the language system is based on data from language use: empirical and experimental data of linguo-psychological experiments, language acquisition by children, and text corpora [40, p. 130]. The key objective of the approach is to develop a competent theory for analyzing the structure of language as an emergent phenomenon. Language draws on "domain-general socio-cognitive processes, including categorization, association, routinization, generalization, schematization, joint attention, statistical learning, analogy, metaphor, and others" [35, p. 15], involved not only in language production and perception but also in many other cognitive processes, in particular memory, attention, etc. [13; 48]. Grammar of language is seen as a cognitive organization of a speaker's experience with language [12].

Representatives of the usage-based theory of language assume that the essence of language lies in its symbolic nature, and grammar is derived. The ability to communicate with members of their species (conventionally, intersubjectively) is a species-specific biological adaptation of human beings [54]. The grammatical dimension of a language is recognized as a product of historical and ontogenetic processes, the process of grammaticalization in particular. When human beings use symbols to communicate with each other, combining them into patterns, there appear patterns that give rise to grammatical constructions, such as the English Passive Construction, noun phrase construction, or -ed past tense construction. Such constructions are interpreted as linguistic symbols that have their own meaning and are used in communication with a certain intention, for example, the Passive Construction is employed to inform about an entity with which something happens [53, p. 5].

The basic tenets of usage-based language theory are actively adopted in construction grammar research; thus these two approaches are often considered as one framework "usage-based construction grammar" 
[48; 20]. Usage-based model of construction grammar assumes a close connection between language structures and speech utterances; highlighting the interrelation of the language system with other cognitive systems and emphasizing the crucial role of context in the language system functioning [43, p. viii-xxii].

Usage-based construction grammar considers language as a "complex adaptive system" that arose for the purpose of communication and information processing. It is a dynamic system consisting of fluid structures and flexible constraints, determined by domain-general cognitive mechanisms of communication, memory, and information processing [21]. Accordingly, the structure of language is not a priori fixed, but is constantly restructured and reorganized under the influence of domain-general cognitive processes, i.e., is emergent and constructions are understood "to be emergent clusters of lossy memory traces that are aligned within our high- (hyper!) dimensional conceptual space on the basis of shared form, function, and contextual dimensions" [31, p. 7].

Abstract hierarchically structured linguistic representations are built "bottom-up" from successive experiences of a speaker with specific speech units. Grammar of language is seen as a cognitive organization of speakers' experience with language [12].

In contrast to generative grammar, which, according to R. Langacker [45, p. 46] has consistently operated with an archetypal understanding of language as a system of general rules and therefore did not take into account irregular and idiosyncratic phenomena, the usage-based model of construction grammar focuses on real language use and on a speaker's knowledge of this use. Linguistic competence presupposes mastering all units and structures of a language, constituting a complex and diverse set of linguistic representations: highly canonical (core) and highly idiosyncratic (periphery) elements and many units in between. Language is understood as a structured inventory of constructions, some of which are concentrated in a core-like center, and others reside more toward the periphery [53, p. 6].

Usage-oriented construction grammarians support the opinion that the recurrence of individual language units and their sequences is an essential property of a human language [11], and recognize the crucial influence of input data on a speaker's mental grammar formation. Recurrence leads to the conventionalization of categories and associations, as well as to the automatization of these sequences. Recent research in the field shows that all levels of language, from phonetic to morphological and syntactic, are strongly effected by the frequency of 
input data: every time a speaker encounters a word, neural nodes are activated in his brain, and connection strength between them is influenced by frequency of an input word, i.e., token frequency. Frequency of a language unit enhances representation of a language element in a speaker's memory, promotes activation and processing of words, categories, and constructions. The more often a word is used, the stronger the associations in neural nodes, resulting in cognitive entrenchment of this unit in long-term memory [9, p. 4; 37, p. 81].

Frequency effects the entrenchment of lexical units and abstract grammatical patterns (constructions). For example, the sentences John gave Bill a book, Peter sent Mary a letter, She forwarded him a mail have a common meaning 'A CAUSES B to RECEIVE C by V-ing' and effect the entrenchment of the abstract grammatical pattern Subject $_{A} V_{\text {Object }}$ Objectc of the Ditransitive construction [38, p. 5].

Focusing on the recurrence of language units encourages construction researchers to actively involve the data of linguistic corpora and the use of various analytical and quantitative techniques for processing vast arrays of natural linguistic data. The investigation of frequency effects on the functioning of constructions necessitates the use of complex quantitative methods, specifically multidimensional and multifactorial analyses.

Arguably, the usage-based model of construction grammar recognizes language as a dynamic system of emergent constructions, the linguistic status of which is determined by their recurrence in speech.

\section{Language computer-modeling schools of construction grammar \\ Fluid Construction Grammar (FCG) is developed by a team of} researchers headed by L. Steele in the Artificial Intelligence Laboratory at the University of Brussels and the Sony Computer Laboratory in Paris to investigate the mechanisms of language evolution using computer models. FCG represents a fully operational and computer-implemented formalism for structural grammars, which offers a unified mechanism for parsing and producing language [14, p. 259; 52]. Flexible construction grammar integrates many concepts from modern computational linguistics, such as feature structure and language processing based on the principle of unification [8; 56]. The school utilizes a fundamental definition of a grammatical construction, but emphasizes the relationship of constructional semantic meaning to bodily and sensory-motor experience. Fluid Construction Grammar adopts a cognitive-oriented tenet, according to which the meaning of all language signs includes 
mental modeling (simulation) and they are completely dependent on the basic image schemas.

Embodied Construction Grammar (ECG) (B. Bergen, N. Chang) focuses on computer modeling of cognitive and neural mechanisms underlying speech behavior of human beings. The framework aims at identifying the mechanisms of generation, processing, and storage of basic grammatical structures in a speaker's mind [6; 7].

ECG applies a traditional definition of a grammatical construction as a "form-meaning" pairing, explicating its functional, semantic and pragmatic properties in cognitive schemas organized into semantic primitives. The analytical tool of semantic specification (semspec) allows to establish and systematize the principles of speech generation by a speaker on the basis of constructions in the communication process.

The element "embodied" in the nomination of the school indicates that semantics of a construction is instantiated by semantic schemes whose metalanguage represents the patterns of neural activity in a human brain under the influence of certain stimuli. For instance, semantic specification of the verb of physical influence 'slap' in the formalism of ECG [4, p. 93] is presented in the diagram in Fig. 8:

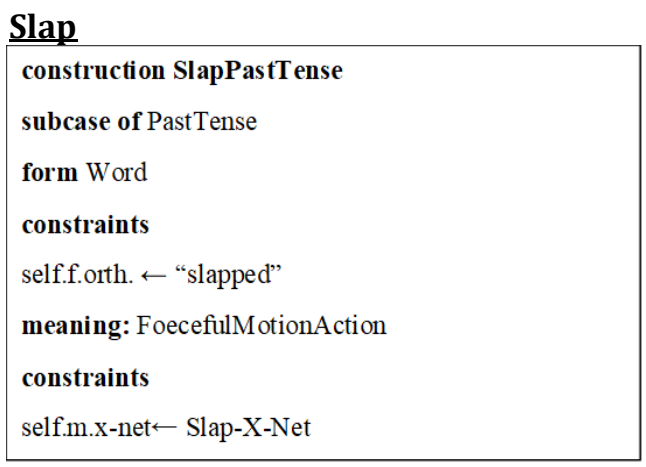

\section{Fig. 8. Representation of the verb "slap" in the formalism of Embodied Construction Grammar}

ECG semantic specification schemas represent the nodes of executive networks or $\mathrm{x}$-nets that model the aspectual structure of an event construed by a particular construction and support dynamic inferences. 


\section{Conclusions}

The presented study of theoretical and methodological architecture of current constructional schools has shown that construction grammar is a thriving field of grammatical theorizing, as manifested by the variety of approaches within it. This comprehensive and usage-based linguistic theory is characterized by an integrative approach to language study: units of all language levels are linguistic constructions of varying degrees of structural complexity and abstraction. By filling in the gaps in both traditional and formalist descriptions of language that have not paid sufficient attention to a number of linguistic phenomena, construction grammar blurs the boundaries between vocabulary and grammar, semantics and pragmatics, meaning and use and represents language as a holistic organism. Such a holistic approach to language units aptly reflects the reality of mental activity, based on uniform cognitive mechanisms and carried out on a single language substrate.

Consolidation of complementary and mutually informative approaches distinguishes construction grammar as a recent dynamically developing cognitive linguistic framework. Regardless of diverse views on, inter alia, a universal status of linguistic constructions, their quantity, and types, application of elaborate notation systems of constructional modeling, all construction-oriented schools share a common theoretical and methodological basis, expressed in the following principles:

- The analysis of language units of different levels is carried out in terms of (linguistic) constructions, whose form and meaning are combined in conventional and non-compositional ways. Constructions vary in the degree of generality/ specificity and syntactic complexity from "fully lexicalized" and "idiomatic" to abstract, productive schemas, embracing units of all language levels.

- A linguistic construction is a holistic semiotic model, a specific configuration of structural elements associated with a semantic/ discursive function. As non-compositional, (completely) productive, cognitively entrenched and complex pairings, constructions are representation patterns of all language knowledge - syntax, morphology and lexicon, serving a cognitive-semantic interface to knowledge structures behind their plane of expression.

- A semantic component of a linguistic construction is directly mapped onto its surface syntactic structure without any transformations or derivations. 
- Constructions form a structured inventory (construct-i-con), i.e., organized in vast constructional networks, whose nodes are combined by relations of inheritance, polysemy, and synonymy.

- Constructions are sensitive to the frequency and contexts of use. The structure of language is shaped by its use.

- Similar constructions vary in different languages, and cross-language generalizations are explained not by linguistic universals, but by general cognitive, pragmatic, and information processing factors. The functions associated with specific constructions are recognized as universal.

According to A. Goldberg, the principal advantage of the constructional framework is its "descriptive adequacy", which allows to embrace both linguistic generalizations and idiosyncrasies [29, p. 11]. From this perspective, language is viewed as a holistic entity in which none of the language levels is autonomous or "nuclear", instead all levels work simultaneously in a construction. All units bear equal significance for the description of language and a uniform analysis is applied both to idiosyncratic "periphery" and "nuclear" linguistic units. Language levels are interconnected, so no elements or operations work on just one of them. No language unit or structure can gain a central or more important status, and linguistic analysis is not limited to "nuclear" central cases, ignoring the study of epigrammatic phenomena and exceptions to the rules. On the contrary, all units are equally significant for the description of language grammar, and the same unified analysis is applied to the idiosyncratic "periphery" and the "nuclear" linguistic units. The analysis at different language levels is not sequential but simultaneous, and elements of one level are constantly available and can interact with elements of another level. Construction grammar seeks to cover all levels of language with the intention of comprehending each language in its entirety by inventorying all constructions in it.

Given the reported advantages and undeniable potential of construction grammar theory, in our future research we will employ the procedural apparatus of the framework to the study of specific linguistic material (in our case, English detached nonfinite constructions with an explicit subject) based on extensive corpus data with application of sophisticated quantitative methods.

\section{References:}

1. Жаботинская С.А. Генеративизм, конитивизм и Семантика лингвальных сетей. Doctrina multiplex, veritas una. Учень багато, 
істина одна : збірник праць до ювілею І.Р. Буніятової / Київський унт ім. Б. Грінченка. К.: Ун-т ім. Б. Грінченка, 2018. С. 99-141.

2. Ситар Г.В. Синтаксичні фразеологізми в українській мові: структурно-семантичний, прагматичний і прикладний виміри: дис. ... д-ра філол. наук: 10.02.01. Київ, 2018. 516 с.

3. Сосюр Ф. де Курс загальної лінгвістики. Пер. 3 фр. А. Корнійчук, К. Тищенко. К.: Основи, 1998. 324 с.

4. Тищенко С.В. Воплощенная грамматика конструкций: теоретические основы и методы анализа. Университетские чтения, 2016. Пятигорск: Пятигорский государственный лингвистический университет, 2016. С. 90-95.

5. Храковский В. С. Вербоцентрический подход к конструкциям и/ или грамматика конструкций. Смыслы, тексты и другие захватывающие сюжеты : сб. ст. в честь 80-летия И. А. Мельчука. М.: Языки славянской культуры, 2012. С. 288-300.

6. Bergen B., Chang N. Embodied Construction Grammar in Simulation-Based Language Understanding. Construction Grammars: Cognitive Grounding and Theoretical Extensions. Amsterdam: John Benjamins Publishing Company, 2009. P. 147-190.

7. Bergen B., Chang N. Embodied Construction Grammar. The Oxford Handbook of Construction Grammar. Oxford: Oxford University Press, 2013. P. 168-190.

8. Beuls K., van Eecke P., Cangalovic V. A Computational Construction Grammar Approach to Semantic Frame Extraction. Linguistics Vanguard. 2021. № 7(1). 20180015. https://doi.org/10.1515/lingvan-2018-0015

9. Blumenthal-Dramé A. Entrenchment in Usage-based Theories: What Corpus Dara Do and Do Not Reveal About the Mind. Berlin, Boston: De Gruyter Mouton, 2012. 278 p.

10. Boas H. C., Fried M. Introduction. Grammatical constructions. Back to roots. Amsterdam/ Philadelphia: John Benjamins, 2005. 253 p.

11. Bybee J. The Phonology of the Lexicon: Evidence from Lexical Diffusion. Usage-Based Models of Language. Cambridge: Cambridge University Press, 2000. P. 65-85.

12. Bybee J. From Usage to Grammar: The Mind's Response to Repetition. Language. 2006. № 82. P. 711-733.

13. Bybee J. Usage-based Theory and Exemplar Representations of Constructions. The Oxford Handbook of Construction Grammar. Oxford: Oxford University Press, 2013. P. 49-69. 
14.Chang N., De Beule J., Micelli V. Computational Construction Grammar: Comparing ECG and FCG. Computational Issues in Fluid Construction Grammar. Berlin: Springer, 2012. P. 259-288.

15.Croft W. Radical Construction Grammar: Syntactic Theory in Typological Perspective. Oxford: Oxford University Press, 2001. 377 p.

16.Croft W. Logical and typological arguments for Radical Construction Grammar. Construction Grammars: Cognitive grounding and theoretical extensions. Amsterdam: John Benjamins Publishing company, 2005. P. 273-314.

17. Croft W. Construction Grammar. The Oxford Handbook of Cognitive Linguistics. Oxford: Oxford University Press, 2007. P. 463-508.

18. Croft W. Radical Construction Grammar. The Oxford Handbook of Construction Grammar. Oxford: Oxford University Press, 2013. P. 211-232.

19. Croft W., Cruse A. D. Cognitive Linguistics. Cambridge: Cambridge University Press, 2004. 374 p.

20.Diessel H. Usage-based Construction Grammar. Handbook of Cognitive Linguistics. Berlin Boston: Walter de Gruyter, 2015. P. 296-321.

21.Diessel H. Usage-based linguistics. Oxford Research Encyclopedia of Linguistics. New York, 2017. URL: http://linguistics.oxfordre.com/view/10.1093/acrefore/9780199 384655.001.0001/acrefore-9780199384655-e-

363?rskey=ivWwgv\&result=2 (дата звернення: 01.10.2021)

22. Evans V., Green M. Cognitive Linguistics: An Introduction. Edinburgh: Edinburgh University Press, 2006. 830 p.

23. Fillmore Ch. J. The Mechanisms of "Construction Grammar". BLS. 1988. №14. P. 35-55.

24. Fillmore Ch. J. Syntactic Intrusions and the Notion of Grammatical Construction. Proceedings of the Eleventh Annual Meeting of the Berkeley Linguistic Society. 1985. P. 73-86.

25.Fillmore Ch. J. Berkeley Construction Grammar. The Oxford Handbook of Construction Grammar. Oxford: Oxford University Press, 2012. P. 111-132.

26. Fillmore Ch. J., Kay P., O'Connor C. Regularity and Idiomaticity in Grammatical Constructions: The Case of 'Let alone'. Language. 1988. № 64. P. 501-538.

27.Fried M., Östman J.-O. Construction Grammar. A Thumbnail Sketch. Construction Grammar in Cross-Language Perspective. Amsterdam/ Philadelphia: John Benjamins Publishing, 2004. P. 11-86. 
28. Goldberg A. E. Constructions: A Construction Grammar Approach to Argument Structure. Chicago: University of Chicago Press, 1995. 265 p.

29. Goldberg A. E. Constructions at Work: The Nature of Generalization in Language. Oxford: Oxford University Press, 2006. 280 p.

30. Goldberg A. E. Constructionists Approaches. The Oxford Handbook of Construction Grammar. Oxford: Oxford University Press, 2013. P. 15-31.

31. Goldberg A. E. Explain Me This: Creativity, Competition, and the Partial Productivity of Constructions. Princeton, Oxford: Princeton University Press, 2019. 195 p.

32.Gries St. Th., Ellis N.C. Statistical Measures for Usage-Based Linguistics. Language Learning. 2015. №65 (S.1). P. 1-28.

33. Groom N. Construction Grammar and the Corpus-Based Analysis of Discourses: the Case of the WAY IN WHICH Construction. International Journal of Corpus Linguistics. 2019. № 24(3). P. 335-367.

34. Hilpert M. Constructional Approaches. The Oxford Handbook of English Grammar. Oxford: Oxford University Press, 2020. P. 106-123.

35. Hilpert M. Ten Lectures on Diachronic Construction Grammar. Leiden, Boston: Brill, 2021. 281 p.URL: https://brill.com/view/title/56854 (дата звернення: 02.10.2021).

36. Hoffmann Th. Construction Grammars. The Cambridge Handbook of Cognitive Linguistics. Cambridge: Cambridge University Press, 2016. P. 310-329.

37.Hoffmann Th. Multimodal Construction Grammar: From Multimodal Constructs to Multimodal Constructions. The Routledge Handbook of Cognitive Linguistics. New York, London: Routledge, Taylor and Francis Group, 2021. P. 78-92.

38. Hoffmann Th. Preposition Placement in English: A Usage-Based Approach. Cambridge: Cambridge University Press, 2011. 297 p.

39. Hoffmann Th., Trousdale G. Construction Grammar: Introduction. The Oxford Handbook of Construction Grammar. Oxford: Oxford University Press, 2013. P. 1-14.

40. Janda L. A. Linguistic Profiles: A Quantitative Approach to Theoretical Questions. Language and Method. 2016. № 3. P. 127-145.

41.Janda L. A. Quantitative perspectives in Cognitive Linguistics. Review of Cognitive Linguistics. 2019. № 17:1. P. 7-28.

42. Kay P. Construction Grammar. Handbook of Pragmatics. Amsterdam \& Philadelphia: John Benjamins, 1995. P. 171-177. 
43. Kemmer S., Barlow M. Introduction: A Usage-Based Conception of Language. Usage-Based Models of Language. Cambridge: Cambridge University Press, 2000. P. i-xxvii.

44. Lakoff G., Johnson M. Metaphors We Live By. Chicago, Lond on: The University of Chicago Press, 1984. 242 p.

45. Langacker R. W. Foundations of Cognitive Grammar, Vol. I: Theoretical Prerequisites. Stanford: Stanford University Press,1987. 516 p.

46. Ohori T. Construction Grammar as a Conceptual Framework for Linguistic Typology: A Case from Reference Tracking. Grammatical Constructions. Back to the roots. Amsterdam/ Philadelphia: John Benjamins Publishing, 2005. P. 215-237.

47.Östman J.-O., Fried M. Historical and Intellectual Background of Construction Grammar. Construction Grammar in a Cross-Language Perspective. Amsterdam/ Philadelphia: John Benjamins, 2004. P. 1-10.

48.Perek F. Argument Structure in Usage-Based Construction Grammar. Experimental and Corpus-Based Perspectives. Amsterdam/ Philadelphia: John Benjamins, 2015. 243 p.

49. Potapenko S. I. Constructions in English: from Paradigmatic to Syntagmatic Relations. Лiтература та культура Полісся. Серія “Філологічні науки". 2017. Вип. 89. С. 172-180.

50.Sag I. A. Sign-based Construction Grammar. An Informal Synopsis. Sign-Based Construction Grammar. CSLI Publications, 2012. P. 69-202.

51. Sag I. A., Boas H.C., Kay P. Introducing Sign-Based Construction Grammar. Sign-Based Construction Grammar. CSLI Publications, 2012. P. 1-28.

52. Steels L. Design Patterns in Fluid Construction Grammar. Amsterdam, Philadelphia: John Benjamins Publishing Company, 2011. 332 p.

53. Tomasello M. Constructing a Language. A Usage-Based Theory of Language Acquisition. Cambridge, London: Harvard University Press, 2003. $388 \mathrm{p}$.

54.Tomasello M. What Kind of Evidence Could Refute the UG Hypothesis? Studies in Language, 2004. № 28. P. 642-644.

55.van Eynde F. Sign-Based Construction Grammar: A Guided Tour. Journal of Linguistics. 2016. № 52(1). P. 194-217.

56.van Trijp R. Making Good on a Promise: Multi-dimensional Constructions. Belgian Journal of Linguistics. 2020. № 34. P. 357-370. 